\title{
ЛИНГВИСТИКА
}

\author{
М.А. Шлигель-Мильх
}

\section{СТРУКТУРА МИФА КАК ПРИНЦИП ТЕКСТОВОЙ ОРГАНИЗАЦИИ НА ПРИМЕРЕ ПОВЕСТИ Г. ГЕССЕ «ДУША РЕБЕНКА»}

\begin{abstract}
Аннотация. Предметом исследования является структура мифа. Писатели эпохи модернизма совершили экзистенциальный возврат к мифологическим истокам, истокам существования человеческой культуры и прецедентным текстам священных Писаний, передавших человеческим языком слова Бога, Логос. Мир, таким образом, понимается как синтез божественного Логоса и человеческого языка в св. Писаниях и Преданиях. Постоянное обращение к мифам свидетельствует об их долговечности. Мир получает в литературном произведении новое обличье, а его структура встраивается в структуру текста. Герменевтика как метод толкования рассматривает текст как слепок некоего события в мире, толкует части как равные целому, стремится при интерпретации держать в фокусе внимания целостную структуру события, запечатленного в тексте. Герменевтический анализ начинается с конкретных языковых структур и ведет к раскрытию духовных смыслов. Основным выводом проведенного исследования является установка того факта, что миф является двухуровневой системой с двумя типами отношений между его структурными элементами: парадигматическим и синтагматическим, на которые проецируются структурные элементы художественного текста. Схема мифа берет участника мифического события в плен, оставляя лишь иллюзию свободы действия, подчиняет своей истине.
\end{abstract}

Ключевые слова: Модернизм, мифология, логос, герменевтика, парадигматический уровень, синтагматический уровень, индекс, миф, синтез, структура мифа.

Abstract. The subject of the present research is the myth structure. Modernist writers made an existential return to mythological sources, origins of human culture and precedent texts of Scriptures conveying the words of God (Logos) through human language. Thus, myth is understood as the synthesis of Logos and human language that can be found in Scriptures and Legends. The fact that humans keep returning to myths proves that myths are long lived. In a literary work myth acquires a new look and the myth structure is embeded in the text structure. Being an interpretation method, Hermeneutics views text as an impression of an event and interprets parts as being equal to the whole, thus trying to focus on the integral structure of an event described in a text. Hermeneutic analysis starts with analyzing particular language structures and leads us to understanding spiritual meanings. The main conclusion of the research is the statement that myth is a two-level system with two types of relations, paradigmatic and syntagmatic, between structural elements of a literary text. The myth scheme captures a participant of a mythological event, thus leaving only an illusion of freedom while bending to its will and truth.

Key words: myth, index, syntagmatic level, paradigmatic level, Hermeneutics, logos, mythology, modernism, synthesis, myth structure.

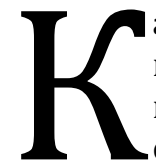
ак писателю-модернисту, Г. Гессе, отдавшему в своем творчестве дань немецкому романтизму, было свойственно обращаться в своем творчестве к мифам. «Провозгласив идею «новой мифологии», романтики первыми сделали миф принципом художественного творчества, и писатели-модернисты впоследствии следовали именно романтической традиции использования «древнего наследия» человечества» [12, с. 131], «они искали Логос, существенный смысл бытия, выраженный в языке» [6, с. 41] и стремились выразить его в литературном произведении.

Истоком всего творчества теоретик романтизма Ф. Шлегель видел именно мифологию [16, с. 200]. Творчество должно вернуть мифологии ее первоначальный смысл, она должна объединять чувственное начало с духовным началом, объединить разум и чувства, конечное с бесконечным, открыть в каждой частице божественное, по выражению Шлегеля «Allgötterei». В письме к Новалису [16, с. 409] 
Шлегель пишет, что любое произведение должно стать Библией в том смысле, что оно должно стать первым в своем роде творением искусства, подобно тому, как Библия стала творческой переработкой божественного Логоса при помощи человеческого языка. Миф - это трансцендентная реальность, запечатленная сознанием в снятом виде, и выраженная при помощи языковых средств текста.

Согласно Н.О. Гучинской миф следует рассматривать в двух значениях: „во вневременном - как всякое первичное сотворение языка, и как религиозно-речевое творчество, продуктом которого является текст" [8, с. 27]. Автор указывает на метафизическую природу мифа и предлагает следующую герменевтическую концепцию: „Вначале был Божественный Логос, затем явился миф как человеческий язык, сохранившийся в текстах - продуктах речевого творчества. Логос - язык божественный, миф - человеческий, Логос первичен, миф - вторичен“ [8, с. 27]. Миф является интерпретацией Божественного Логоса человеческим языком, синтезом конечного и бесконечного в чувственно воспринимаемом языковом знаке. Он использует семиотический потенциал естественного языка для построения новой системы смыслов, объединяющей физический и метафизический миры. Благодаря этому «потустороннее» обретает физическую форму, входит в этот мир и переживается как некая сверхдействительность. Поэтому мифы метаисторичны, они повествуют о свершившемся как о неком прасобытии, моменте вторжения трансцендентной реальности в пределы физического мира. „В прасобытии, рассматриваемом в качестве священного, видят не просто прошлое, которое можно понимать или которому можно подражать, но вечно настоящее или, в крайнем случае, постоянно и идентично повторяющееся" [15, с. 72].

Событие, описываемое в мифе, всегда актуально. Духовный смысл исхода евреев из Египта, описанный в библейской книге Исход, ежегодно переживается во время празднования Песаха, как заповедано: «Дабы помнил ты день исхода твоего из земли Египетской во все дни жизни твоей» (Втор. 16,3) События того времени стали одним из основных мотивов исторического наследия народа Израиля. Исход стал восприниматься как образ спасения народа во все времена: «Посему вот приходят дни, говорит Господь, когда не будут уже говорить: «Жив Господь, который вывел сынов Израиля из земли Египетской», но жив Господь, который вывел сынов Израиля из земли Северной и из всех земель, в которые изгнал их, - ибо возвращу их в землю их, которую Я дал отцам их» (Иер. 16, 14-15).

Миф передает слова и действия Бога так же как действия человека. Слово Бога становится словом человеческим (святым Писанием), оно «становится плотью» для того, чтобы его можно было воспринять. С помощью языка открывается живущий Бог в самих адресатах (reveal the living God Himself in our own selves) [19, с. 133]. Постоянное упоминание мифа и память о нем придает чувство сопричастности событиям, описанным в нем, актуализирует (re-actualize) миф и делает ему сопричастным посредствам памяти (re-member) [19, с. 124]. Для правильного его прочтения необходимо добровольно подчиниться истине мифа в тексте для того, чтобы миф начал действовать, тогда божественная истина проникнет в разум, и разум будет развиваться согласно этой истине: «If the mind and its reactions are brought into willing obedience to that truth, the divine truth continues to permeate the mind even more and the mind develops with it endlessly» [19, с. 135].

В переживании текста герменевтика видит основу правильного толкования. В толкователе должен непременно присутствовать тот же Логос, что и в тексте. Филологическая герменевтика, как и сакральная, “берет всякий объект истолкования в неразрывной связи с рефлектирующим сознанием, с субъективностью интерпретатора в единстве осознающего и осознаваемого, в слиянии субъективного и объективного - стремится к живой нерасчлененности субъекта и объекта" [1, с. 34].

В критической ситуации человек обращается к мифу как к свидетельству о сущностном измерении реальности, ищет ответ на основные вопросы своей жизни. Миф задает смысл жизни, любая жизненная ситуация может трактоваться в связи с мифом, который позволяет “мыслить о бытии как о бытии смысла этого бытия» $[10$, с. 88]. «Миф дает ответы на жизненные вопросы или хотя бы указания, он извлекает алчущего смысла человека из мира конечных величин, размыкает его существование, ограниченное смертью, в вечность. Он имеет непосредственное отношение к человеку, к его жизни, дает средства и задает способ существования и ориентации в мироздании, культурной самореализации» [9, с. 153].

Следующей особенностью мифа является его моделирование действительности. Значение мифов, их ценность связаны не с их прямой физической данностью, а, как было отмечено ранее, с присущим им качеством «быть воспроизведением прадействия», повторением мифического образца. «Действие обретает смысл, реальность исключительно в той мере, в какой оно возобновляет некое прадействие» $[17$, с. 26]. «Миф является священной, повторяющейся моделью, представляет собой определенную грамматику поведения» $[11$, с. 343]. Моделирование сводится к субституции физических предметов трансцендентной реальности 
мифа, которая не отражает реальности физического мира, т.к. не сообщает о нем истины, она задает определенный способ рефлексии, действия и восприятия.

Миф усваивается согласно его собственной установке: читатель переживает миф как историю относительно правдивую и нереальную. «Миф ничего не скрывает и ничего не демонстрирует - он дебормирует. Его тактика не правда и не ложь, а отклонение» [4, с. 289]. Выбор между правдой и ложью уничтожит миф. «Миф - максимальное развитие, зашедшее далеко вперед сравнительно со свершившимся на самом деле. В мифе выгоняется на поверхность вся скрытая подземная жизнь явления, пусть это будут положительные силы, там лежащие, пусть это будут разрушительные. Миф усиление внутреннего смысла, заложенного в художественный образ, и смысл при этом доводится или, скажем, возвышается до вымысла» [5, с. 47]. Миф становится причиной происходящего, его природой, «миф прочитывается как фактическая система, будучи в действительности лишь системой семиологической» [4, с. 291].

Первоначально мифу присуща презумпция сакральности, миф трактовался как слово о богах, но со временем нуминозное в его составе может «обесцениться» и миф может «наполнится чисто профанным содержанием» [15, с. 72]. Процесс отдаления от изначальной сакральности наблюдается в литературном творчестве во время художественной переработки мифа автором. Согласно А. Л. Вольскому профанизация мифа, т.н. вторичная сакрализация текста происходит при создании автором литературного произведения вторичной символической системы, подражающей символике первично сакрального текста, в данном случае - Библии [7, с. 88]. В повести Германа Гессе «Душа ребенка» первичным сакральным текстом служит библейская история о грехопадении. В обоих текстах присутствует одинаковая событийная последовательность.

Герман Гессе, выросший в семье миссионеров, с детства был под влиянием религиозного учения пиетизма. Тексты священного Писания стали для него прецедентными и оказывали влияние на одиннадцатилетнего мальчика. Повесть «Душа ребенка» открывает внутренний конфликт моральных требований с природными влечениями. Герой хочет оставаться верным высоким религиозным идеалам, но ощущает дьявольский соблазн совершить проступок. Чувство вины ребенка, совершившего проступок был бы вполне естественным, однако строгое религиозное воспитание формирует огромный комплекс вины перед Богом и отцом, и проступок воспринимается как «грех».
Миф может быть представлен в виде двухуровневой структуры, имеющей «синтагматическое и парадигматическое измерения» [13, с. 97]. Данные в парадигматическом измерении являются общими структурными единицами мифа, пучками отношений и содержат постоянные данные, обеспечивающие устойчивость мифа при создании его многочисленных вариантов, как, например, при переводе, создании идеологий и использовании его как основы литературного творчества. При художественной обработке данные парадигматического уровня объединяют миф с внутренним миром художественного произведения. Единицы, находящиеся в синтагматическом отношении, представляют собой данные конкретной речевой ситуации, отличающиеся от основного содержания мифа. Сопоставительный анализ текста Гессе с 3 главой книги Бытие позволяет выделить три группы отношений на парадигматическом уровне: искушение, преступление, изгнание.

Структура мифа о грехопадении является принципом текстовой организации повести «Душа ребенка». Она способствует выстраиванию отношений между элементами текста. «В любом тексте существует два типа отношений - дистрибутивные, горизонтальные, когда отношения устанавливаются между элементами одного уровня, и интегративные, вертикальные, при которых отношения устанавливаются между единицами разного уровня. Понять какое-либо произведение - значит не просто проследить, как развертывается его сюжет, это значит также спроецировать горизонтальные связи, образующие повествовательную нить на имплицитно существующую вертикальную ось» [3, с. 202]. Структура текстовой организации вбирает в себя структуру мифа, сливается с ней. Дистрибутивные отношения в тексте проецируются на синтагматическое измерение мифа, интегративные - на парадигматическое. Миф вторгается в художественный мир текста, подменяет собой его структуру. Вторжение мифа выражено также такими интегративными единицами внутри текста как индексы. «Индекс отсылает не к следующей за ним дополняющей единице, а к более и менее определенному представлению, необходимому для раскрытия сюжетного смысла, корреляты индексов всегда располагаются выше, чем они сами» [3, с. 206]. В данном случае индексы отсылают к постоянным структурным единицам мифа

Первым общим структурным элементом является искушение. В обоих текстах присутствует фигура искусителя, которого отличает наличие некоего знания, пока еще скрытого для героев. В библейском тексте Змей был хитрее всех: "Aber die Schlange war listiger als alle Tiere auf dem Felde, die Gott der 
Herr gemacht hatte (1. Mose 3,1). Искушение состоит в желании быть равным Богу, принадлежать божественной реальности. Змей убеждает съесть плод, после чего, как он утверждает, люди станут богами. «An dem Tage, da ihr davon esst, werden eure Augen aufgetan, und ihr werdet sein wie Gott und wissen, was gut und böse ist" (1. Mose 3, 5). Искушение заключается в желании противопоставить два мира, два типа бытия - мир райского сада и мир Бога, усомниться в справедливости жизни в Эдеме и выразить претензию на бытие равное Богу.

Искусителем для героя Гессе, обладателем знания о другой реальности, был Оскар Вебер. Тайна Вебера заключается в том, какое место он занимает в мире взрослых. Как и в истории о грехопадении, герой не доволен своим детским миром, и дальнейшее преступление является его претензией на жизнь взрослого. «An Weber war nichts für mich liebenswert als sein großes Geheimnis, kraft dessen er den Erwachsenen näher stand als ich, in einer schleierlosen, nackteren, robusteren Welt lebte als ich mit meinen Träumen und Wünschen. Und ich fühlte voraus, dass er mich enttäuschen würde, dass es mir nicht gelingen werde, ihm sein Geheimnis und den magischen Schlüssel zum Leben zu entreißen" [18, c. 380]. Герой испытывает тягу к тому миру взрослых, которые живут не так, как он в мечтах.Такие парни как Вебер были увереннее более защищены в этом мире: "Sie standen anders und gesicherter in dieser Welt als ich“ [18, с. 380]. Они были намного успешнее, чем он, могли зарабатывать, находили интересные вещи. «Natürlich fanden solche Knaben auch Hufeisen, Geld und Stücke Blei auf der Straße, bekamen Lohn für Besorgungen, kriegten in Läden allerlei geschenkt und gediehen auf jede Weise" [18, с. 380]. В то время как он должен еще взрослеть, ходить в школу и воспитываться. Взрослые для мальчика представляются некими полу-божествами. «Die Erwachsenen taten, als sei die Welt vollkommen und als seien sie Halbgötter, wir Knaben aber nichts als Auswurf und Abschaum" [18, c. 381].

При общем структурном элементе парадигматического уровня тексты отличаются единицами синтагматического уровня. В библейском тексте люди, совершая грех, не сомневались в том, что Бог от них что-то скрывает, и они приобретут те качества, о которых говорил Змей. Они они на самом деле стали другими. «Siehe, der Mensch ist geworden wie unsereiner und weiß, was gut und böse ist" (1. Mose $3,22)$. В тексте Гессе в момент искушения герой знает, что крадет инжир под влиянием первородного греха: „Der Dämon schlich durchs Haus, Erbsünde nagte am Herzen» [18, c. 383], но знает заранее, что обречен на провал, что так и не узнает тайну мира взрослых и не будет в него принят. «Und ich fühlte voraus, dass er mich enttäuschen würde, dass es mir nicht gelingen werde, ihm sein Geheimnis und den magischen Schlüssel zum Leben zu entreißen“. Следующим отличием повести «Душа ребенка» является отношение героя к взрослым, принадлежащим другому миру. Он чувствует себя отброшенным им, по его мнению, дети всего лишь „Auswurf und Abschaum». Подобного отношения Адама и Евы к Богу в библейском тексте нет.

Второй общий структурный элемент - преступление. Люди в Эдеме срывают плод познания Добра и Зла. Герой литературного текста крадет инжир в кабинете отца. Преступление совершается под властью зла - Змея, дьявола. Ева указывает на Змея как на виновника своего преступления. «Die Frau sprach: Die Schlange betrog mich, so dass ich aß» (1.Mose 3,13$)$. Ребенок крадет инжир по той же причине. «Ich tat es, um den Zwang zu folgen, der mich fast erstickt hätte, dem Zwang, Böses zu tun» [18, c. 386]. В обоих текстах присутствует желание скрыть свое преступление посредствам лжи. «Und Gott der Herr rief Adam und sprach zu ihm: Wo bist du? Und er sprach: ich hörte dich im Garten und fürchtete mich; denn ich bin nackt, darum versteckte ich mich". Адам испуган и приводит свою наготу в качестве оправдания, почему не вышел на зов Бога. Лжет сын отцу за обеденным столом, называя головную боль причиной своего мрачного настроения, стараясь скрыть свои переживания из-за соделанного, и не выдать себя. «Du siehst heute schlecht aus", sagte mein Vater über den Tisch weg. "Fehlt dir etwas?" hörte ich seine Stimme wieder. Ich log, ich sagte, ich habe Kopfweh" [18, c. 388].

За преступлением следует изгнание. Бог изгоняет людей из райского сада. «Da wies ihn Gott der Herr aus dem Garten Eden und trieb den Menschen hinaus" (1. Mose 3, 23-24) Герой Гессе осознает свое преступление и знает, что за ним последует наказание, ему не остается ничего, кроме бегства. «Jetzt gab es nichts als fliehen, vor dem Vater, vor der Strafe, vor mir selber, vor meinem Gewissen, fliehen und rastlos sein, bis dennoch unerbittlich und unentrinnbar alles kam, was kommen musste" [18, c. 393]. Отдаление от Бога сопряжено с трудностями и бедами, на лице изгнанников в обоих текстах выступает пот. „Im Schweiße deines Angesichts sollst du dein Brot essen" (1. Mose 3, 19). „Ich lief und lief, den Schweiß auf der Stirn, und hinter mit lief meine Schuld und lief groß und ungeheuer der Schatten meines Vaters als Verfolger mit" [18, c. 394].

Внешняя среда, в которую изгоняются / бегут герои, и информация о которой располагается на синтагматическом уровне, различна своим внутренним и внешним состоянием. Отныне земля проклята Богом из-за преступления Адама и Евы. Господь говорит первым людям: „Verflucht sei der 
Acker um deinetwillen» (1. Mose 3, 17)! Земля становится также внешне агрессивной, которую они в поте лица должны возделывать и добывать свой хлеб."Mit Mühsal sollst du dich von ihm nähren die Leben lang. Dornen und Disteln soll er dir tragen» (1. Mose 3, 17-18) Для героя литературного произведения внешняя действительность остается прежней, но при этом изменяется восприятие объектов внешнего мира, все становится отравленным и опустошенным. „Alles war noch wie immer, Wald und Fluss, Farnkräuter und Blumen, Burg und Ameisenhaufen, und doch alles wie vergiftet und verwüstet" $[18$, c. 393].

Следующее отличие вторичного текста возвращение героя Гессе. „Ich wusste, dass ich zurückkommen würde. Man kam immer zurück, jedesmal. Es endete immer so. Man konnte nicht fort" $[18$, c. 394]. Кроме того, в текстах бегство героев описывается различными предикатами. В библейской истории используются предикаты weisen aus и hinaustreiben указывают на изгнание Богом, в то время как в тексте Гессе используются предикаты fliehen и laufen, указывающие на добровольный побег. Согласно Арутюновой [2, с. 43], значение предиката - это „кадр, выхваченный из киноленты жизни, он воспринимается на фоне смены ситуаций и в их контексте“. Предикатные слова описывают свойства и отношения аргументов, выражают то, что мы думаем о мире, они содержат в себе причинно-следственные схемы, раскрывающиеся во времени и пространстве. Их цель вызвать в воображении читателя определенные образы и картины, а не обременять его дополнительной информацией. Предикаты laufen и fliehen описывают отношения отца и сына и имплицитно включают в свое значение акт преступления, лицо, по отношению к которому было совершено преступление, побег как попытка избежать наказания, муки совести. Отец представляется ему богом, грозным судьей, чей кабинет является храмом. «Hier waren Gericht und Tempel und das „Reich der Vaters» [18, c. 384]. Герой воображает, что отец уже узнал о его проступке, муки совести наталкивают его более того на мысль, что он давно уже подозревает его в воровстве, так как в семье более никто на это не способен. „Denn er wusste natürlich sofort, dass ich der Dieb war. Es gab keine Verbrecher im unserem Haus außer mir, meine Schwester taten nie so etwas, Gott weiß warum" [18, c. 392]. Он - чудовище, обокравший своего отца: „Was war ich für ein Ungeheuer, dass ich diesen Vater so oft betrübt, betrogen und heut bestohlen hatte"! [18, c. 395]. Таким образом, дискриптивная способность предикатов определяется дополнительными имплицитными значениями в семантической структуре, способными вызвать в памяти события, описанные ранее, и указать на дальнейший ход развития событий. Предикаты laufen и fliehen в структуре текста являются как бы свернутой картиной происходящего.

Проведенный анализ позволяет констатировать следующее. Элементы текста, расположенные дистрибутивно, повествуют о событиях, разворачивающихся в пространстве и времени. Сначала фигура искусителя, того, кто знает намного больше, чем искушаемый, толкает на мысль о совершении преступления. Герои желают быть как боги, измениться внутренне и внешне, получить новый опыт. Затем, несмотря на запрет, совершается преступление, съедается плод дерева познания Добра и Зла в райском саду и инжир в кабинете отца. И, наконец, настает момент изгнания, при котором меняется как внешнее, так и внутреннее состояние героев, сопряженное с муками и страданиями. Вертикальная ось, общая для первичного сакрального текста и вторичного профанного, проходит через парадигматические структурные элементы мифа. Благодаря этому объекты художественного мира произведения изымаются из конкретноисторического контекста, миф превращается в причину происходящего, становится природой события. Герой повести в своем сознании сливается с объектами мифа - первыми людьми, что приводит в конечном итоге к подчинению истине мифа и его переживанию.

Индексы еще белее связывают трансцендентную реальность с воспринимаемой героем действительностью физического мира. «Der Dämon schlich durchs Haus, Erbsünde nagte am Herzen, riesig, und unsichtbar stand hinter jeder Wand ein Geist, ein Vater und Richter “ [18, c. 383]. „Jetzt passierte etwas, jetzt tat ich Verbotenes und Böses. Niemand erlöste mich, und in mir selber war keine Freiheit, anders zu tun, als der Dämon wollte“ [18, c. 385]. Индексы Dämon, Erbsünde, Verbotenes und Böses непосредственно указывают на события в Эдемском саду, на фигуру искусителя, которому первые люди не смогли противостоять. Герой совершает преступление, „Verbotenes und Böses» перед лицом Бога, отождествляемого в данной ситуации с отцом, хозяином дома, царства закона, строгости и ответственности. «O Gott! Es roch nach Strenge, nach Gesetz, nach Verantwortung, nach Vater und Gott" [18, с. 398]. Коррелятами перечисленных индексов является события, описываемые в первичном сакральном тексте, при их помощи дом героя отождествляется с Эдемом, а отец с Богом.

Миф, как отмечалось, не отражает реальности физического мира, он отражает реальность метафизическую. Обычный детский проступок превращается в событие колоссального значения, в котором муки совести из-за съеденного инжира и страх перед отцом соединяются с кар- 
тинами страшного суда, осознанием дьявольского влечения и присутствием первородного греха. Действительность деформирована вторжением мифа настолько, что объекты реального мира воспринимаются совершенно иначе, чем это есть на самом деле, отец становится грозным судьей, его кабинет - храмом, улицы воспринимаются отравленными и пустынными.

Итак, миф является двухуровневой системой, включающей в себя парадигматическое и синтагматическое измерения. Структурные элементы парадигматического измерения содержат постоянные данные, которые обеспечивают устойчивость и узнавание мифа. Данные синтагматического уровня могут отличаться в разных вариантах мифа в зависимости от конкретных речевых произведений.
Внутри этой системы располагаются структурные части мифа с двумя типами отношений, представленными тексте. Части мифа, расположенные дистрибутивно, содержат информацию о событиях, разворачивающихся в хронологическом порядке. Интегративные текстовые отношения совпадают с парадигматическим измерением мифа, они объединяют конкретное речевое произведение с мифом и задают форму и порядок происходящего, проецируя «священное событие» на социальную жизнь и культуру. Событие мифа начинает существовать вне времени, оно охватывает в одинаковой степени прошлое, настоящее и будущее, определяя ход событий. Схема мифа берет участника мифического события в плен, оставляя лишь иллюзию свободы действия. Миф, отождествляя участников события с объектами «прасобытия», подчиняет их своей истине.

\section{Список литературы:}

1. Абрамов С.Р. Герменевтика: история и теория метода. (Краткий очерк) [Текст] / С. Р. Абрамов. - Майкоп, издательство АГУ, 2001 г. - 318 с.

2. Арутюнова Н.Д. Язык и мир человека [Текст] / Н.Д. Арутюнова. - 2-е изд., испр. - М.: «Языки русской культуры», 1999. - I-XV, 896 c.

3. Барт Р. Введение в структурный анализ повествовательных текстов [Текст] / Р. Барт // Французская семиотика: от структурализму к постструктурализму; пер. с франц. сост. и вступ. ст. Г.К. Косикова. - М.: ИГ Прогресс, 2002.-С. 196-238

4. Барт Р. Мифологии [Текст] / Р. Барт; пер. с фр., вступ. ст. и коммент. С. Зенкина. - 3-е изд. - М.: Академический проект, 2014. - 351 c.

5. Берковский Н.Я. Романтизм в Германии [Текст] / Н.Я. Берковский. - СПб.: Азбука-классика, 2001. - 512 с.

6. Вейз, Дж. Э. Времена постмодерна [Текст] / Дж. Э. Вейз.-Фонд лютеранское наследие. World Wide Printing, 2002

7. Вольский А.Л. От поэтической философии к философской поэзии: опыт герменевтического исследования [Текст]: Монография / А.Л. Вольский. - СПб.: Норма, 2008. - 332 с.

8. Гучинская H.O. Hermeneutica in nuce. Очерки филологической герменевтики [Текст] / Н.О. Гучинская - СПб.: «Церковь и культура», 2002. - 128 с.

9. Ермолин Е.А. Мифокритика в актуальном научном горизонте [Текст] / Е.А. Ермолин //Ярославский педагогический вестник. - 2009 (60).-№3.-С. 152-156

10. Кузнецова А.В. Кузнецов А.В. Мифологическое сознание романтиков в аспекте допредикативных структур архетипичных состояний человеческого духа [Текст] / А.В. Кузнецова, А.В. Кузнецов // Научные ведомости Белгородского государственного университета. Серия: Философия. Социология. Право.-2015.-Т. 33; № 14 (211).-С. 87-91

11. Почепцов Г. Г. Теория коммуникации [Текст] / Г. Г. Почепцов. - М.: «Рефл-бук», К.: «Ваклер»-2001. - 656 с.

12. Прощина Е.T. О романтической концепции мифа (Новалис и Ф. Шлегель) [Текст] // Вестник Нижегородского университета им. Н.И. Лобачевского. Серия: Филология.-2001.-№1.-С. 131-135

13. Силичев Д.А. Философия. Язык. Культура [Текст]: Монография / Д. А. Силичев.-М.: Вузовский учебник: ИНФРА-М, 2014.-311 с.-(Научная книга)

14. Татаринцева И.В. Миф как способ интеллектуального освоения мира в западноевропейском искусстве XIX-XX вв. [Текст] / И. В. Татаринцева // Вестник Тамбовского университета. Серия Гуманитарные науки.-2015.-№8(148).-С. 257-262

15. Хюбнер К. Истина мифа [Текст] / К. Хюбнер; пер. с нем. - М.: Республика, 1996. - 448 с.

16. Шлегель Ф. Эстетика. Философия. Критика [Текст]. В 2 т. Т 2 /Ф. Шлегель; вступительная статья; пер. с нем. Ю.Н. Попова; прим. Ал. В. Михайлова и Ю.Н. Попова. - М.: Искусство, 1983

17. Элиаде М. Избранные сочинения: Миф о вечном возвращении; Образы и символы; Священное и мирское [Текст] / М. Элиаде; перев. с фр. - М.: Ладомир, 2000. - 414 с.

18. Hesse Hermann. Die schönsten Erzählungen [Текст] / Hermann Hesse.-Suhrkamp Verlag.-2006

19. Doorn-Harder Nelly, van. Sacred Text, Revelation and Athority: Remembering and Transmitting [Tекст] / Nelly van DoorHarder // Religious Identity and Renewal in the Twenty-first Century: Christian and Muslim Explorations. Edited by Sinn and Michael Reid Trice, WLF Documentation 60.-Evangelische Verlagsanstalt, Leipzig.-2015

\section{References (transliterated):}

1. Abramov S.R. Germenevtika: istoriya i teoriya metoda. (Kratkii ocherk) [Tekst] / S. R. Abramov. - Maikop, izdatel'stvo AGU, 2001 g. -318 s.

2. Arutyunova N.D. Yazyk i mir cheloveka [Tekst] / N.D. Arutyunova. - 2-e izd., ispr. - M.: «Yazyki russkoi kul'tury», 1999. $\mathrm{I}-\mathrm{XV}, 896 \mathrm{~s}$. 
3. Bart R. Vvedenie v strukturnyi analiz povestvovatel'nykh tekstov [Tekst] / R. Bart // Frantsuzskaya semiotika: ot strukturalizmu k poststrukturalizmu; per. s frants. sost. i vstup. st. G.K. Kosikova. - M.: IG Progress, 2002.-S. 196-238

4. Bart R. Mifologii [Tekst] / R. Bart; per. s fr., vstup. st. i komment. S. Zenkina. - 3-e izd. - M.: Akademicheskii proekt, 2014. $351 \mathrm{~s}$.

5. Berkovskii N.Ya. Romantizm v Germanii [Tekst] / N.Ya. Berkovskii. - SPb.: Azbuka-klassika, 2001. - 512 s.

6. Veiz, Dzh. E. Vremena postmoderna [Tekst] / Dzh. E. Veiz.-Fond lyuteranskoe nasledie. World Wide Printing, 2002

7. Vol'skii A.L. Ot poeticheskoi filosofii k filosofskoi poezii: opyt germenevticheskogo issledovaniya [Tekst]: Monografiya / A.L. Vol'skii. - SPb.: Norma, 2008. - 332 s.

8. Guchinskaya N.O. Hermeneutica in nuce. Ocherki filologicheskoi germenevtiki [Tekst] / N.O. Guchinskaya - SPb.: «Tserkov' i kul'tura», 2002. - $128 \mathrm{~s}$.

9. Ermolin E.A. Mifokritika v aktual'nom nauchnom gorizonte [Tekst] / E.A. Ermolin //Yaroslavskii pedagogicheskii vestnik. - 2009 (60).-№3.-S. 152-156

10. Kuznetsova A.V. Kuznetsov A.V. Mifologicheskoe soznanie romantikov v aspekte dopredikativnykh struktur arkhetipichnykh sostoyanii chelovecheskogo dukha [Tekst] / A.V. Kuznetsova, A.V. Kuznetsov // Nauchnye vedomosti Belgorodskogo gosudarstvennogo universiteta. Seriya: Filosofiya. Sotsiologiya. Pravo.-2015.-T. 33; № 14 (211).-S. 87-91

11. Pocheptsov G. G. Teoriya kommunikatsii [Tekst] / G. G. Pocheptsov. - M.: «Refl-buk», K.: «Vakler»-2001. - 656 s.

12. Proshchina E.T. O romanticheskoi kontseptsii mifa (Novalis i F. Shlegel') [Tekst] // Vestnik Nizhegorodskogo universiteta im. N.I. Lobachevskogo. Seriya: Filologiya.-2001.-№1.-S. 131-135

13. Silichev D.A. Filosofiya. Yazyk. Kul'tura [Tekst]: Monografiya / D. A. Silichev.-M.: Vuzovskii uchebnik: INFRA-M, 2014.-311 s.-(Nauchnaya kniga)

14. Tatarintseva I.V. Mif kak sposob intellektual'nogo osvoeniya mira v zapadnoevropeiskom iskusstve XIX-XX vv. [Tekst] / I. V. Tatarintseva // Vestnik Tambovskogo universiteta. Seriya Gumanitarnye nauki.-2015.-№8(148).-S. 257-262

15. Khyubner K. Istina mifa [Tekst] / K. Khyubner; per. s nem. - M.: Respublika, 1996. - 448 s.

16. Shlegel' F. Estetika. Filosofiya. Kritika [Tekst]. V 2 t. T 2 /F. Shlegel'; vstupitel'naya stat'ya; per. s nem. Yu.N. Popova; prim. Al. V. Mikhailova i Yu.N. Popova. - M.: Iskusstvo, 1983

17. Eliade M. Izbrannye sochineniya: Mif o vechnom vozvrashchenii; Obrazy i simvoly; Svyashchennoe i mirskoe [Tekst] / M. Eliade; perev. s fr. - M.: Ladomir, 2000. - 414 s.

18. Hesse Hermann. Die schönsten Erzählungen [Tekst] / Hermann Hesse.-Suhrkamp Verlag.-2006

19. Doorn-Harder Nelly, van. Sacred Text, Revelation and Athority: Remembering and Transmitting [Tekst] / Nelly van DoorHarder // Religious Identity and Renewal in the Twenty-first Century: Christian and Muslim Explorations. Edited by Sinn and Michael Reid Trice, WLF Documentation 60.-Evangelische Verlagsanstalt, Leipzig.-2015 